\section{Tratamiento antiviral eficaz en pacientes con hepatitis B resistente a la lamivudina}

La lamivudina se emplea para el tratamiento de pacientes con hepatitis B crónica. Sin embargo, a menudo no se logra la eficacia esperada debido a la resistencia que puede presentar el virus de la hepatitis B (VHB) a este medicamento. La tasa de resistencia de dicho virus a la lamivudina después de cinco años de tratamiento puede ascender a $69 \%$. En estos casos se ha utilizado con resultados satisfactorios el tratamiento con adefovir dipivoxil, ya sea solo o en combinación con la lamivudina. El adefovir posee una fuerte actividad antiviral contra cepas silvestres del VHB, tanto in vitro como in vivo.

Se realizó un estudio para evaluar la inocuidad y eficacia del adefovir dipivoxil — solo y en combinación con lamivudina- en pacientes con hepatitis B crónica compensada resistente al tratamiento con lamivudina que estaban recibiendo. En él participaron 59 pacientes con positividad al antígeno $e$ de la hepatitis $\mathrm{B}(\mathrm{HBeAg})$ y pruebas genotípicas de que el VHB era resistente a la lamivudina; valores de alaninoaminotransferasa sérica (ALT) $\geq 1,2$ veces el límite superior normal; y ADN de VHB en concentraciones mayores de $6 \log _{10}$ copias $/ \mathrm{mL}$ a pesar del tratamiento con lamivudina. Los pacientes fueron agrupados aleatoriamente en tres grupos que recibieron diariamente: 1) $10 \mathrm{mg}$ de adefovir dipivoxil, 2) $100 \mathrm{mg}$ de lamivudina, o 3) adefovir dipivoxil además del tratamiento con lamivudina que se estaba aplicando. Se calculó la variación promedio de las concentraciones séricas de ADN del VHB (DAVG) en relación con las concentraciones iniciales, haciendo ponderaciones en función del tiempo hasta llegar a 16 semanas.

Se observó una rápida reducción de las concentraciones séricas del ADN del VHB en aproximadamente cuatro semanas en todos los pacientes que recibieron adefovir dipivoxil; el valor de DAVG a las 16 semanas fue de $-0,07 \log _{10}$ copias/ $\mathrm{mL}$ en el grupo tratado con lamivudina en comparación con $-2,45 \log _{10}$ copias $/ \mathrm{mL}$ y $-2,46 \log _{10}$ copias $/ \mathrm{mL}$ en los grupos que recibieron adefovir dipivoxil más lamivudina y monoterapia con adefovir dipivoxil, respectivamente. Las concentraciones de ALT se normalizaron en 10 (53\%) de los 19 pacientes que recibieron adefovir dipivoxil más lamivudina y en alrededor de $9(47 \%)$ de los 18 pa- cientes que recibieron monoterapia con adefovir dipivoxil, en comparación con un solo paciente $(5 \%)$ de los 19 que recibieron el tratamiento con lamivudina exclusivamente. A las 48 semanas de tratamiento, tres pacientes que recibieron adefovir dipivoxil o adefovir dipivoxil más lamivudina tuvieron resultados negativos en la prueba detectora de $\mathrm{HBeAg}$ y uno tuvo un resultado negativo en la prueba detectora de antígeno de superficie del virus de la hepatitis B. Ninguno de los pacientes tratados con lamivudina solamente tuvo resultados negativos en ninguna de estas pruebas.

Estos datos, limitados a pacientes con enfermedad hepática compensada, indican que el uso del adefovir dipivoxil, solo o añadido al tratamiento ya iniciado con lamivudina, constituye un régimen antiviral eficaz en pacientes con $\mathrm{VHB}$ resistente a esta última. (Peters MG, Hann HH, Martin P, Heathcote EJ, Buggisch P, Rubin R, et al. Adefovir dipivoxil alone or in combination with lamivudine in patients with lamivudine-resistant chronic hepatitis B. Gastroenterology. 2004;126:91-101).

\section{Vinculan la seropositividad al virus del herpes humano 8 con el cáncer de próstata}

El virus del herpes humano 8 (VHH-8) puede constituir un cofactor que propicia el cáncer de próstata, favorecer el desarrollo de lesiones de mayor grado de malignidad o, sencillamente, ser un marcador de la presencia de otras infecciones que tienen un efecto causal directo sobre el desarrollo del cáncer de próstata.

El objetivo de esta investigación fue determinar si existe una asociación epidemiológica entre la infección por el VHH-8 y el cáncer de próstata, para lo cual se comparó la prevalencia de seropositividad al VHH-8 en un grupo de pacientes con cáncer de próstata con la de un grupo testigo, en dos contextos diferentes desde el punto de vista epidemiológico: los Estados Unidos de América (EUA) y Trinidad y Tabago.

Esta investigación abarcó a 452 hombres de Trinidad y Tabago y a 376 hombres de los EUA. Los anticuerpos contra el VHH-8 se detectaron en dos laboratorios independientes mediante el ensayo de inmunofluorescencia indirecta (IFI) o una combinación de electroinmunoensayo enzimático (ELISA) con IFI. 